professional lives - the annual pilgrimage of clinical investigators to this out-of-the-way place. However, I fought a losing battle. The ASCI moved, probably appropriately, given what was happening to Atlantic City, but unfortunately I was correct - something magical had indeed disappeared and has never returned.

The meetings moved in 1977 to Washington, DC, and then to other cities, ultimately settling in Chicago, in order to make travel easier for investigators and trainees from the entire country, as the center of gravity of clinical research moved westward. With the flowering of the medical subspecialties, afternoon and evening sessions were added. However the Tri-Societies could not compete successfully with the meetings of the subspecialty societies. The Society's meetings, held with the AAP, became a series of brilliant "State of the Art" lectures that cut through several disciplines and were delivered by the most creative and accomplished investigators in the country. This format, which continues to the present, is designed to remind us of the common threads linking all clinical research and its dependence on basic biologic science.
However, despite these changes in the meeting, which reflected the evolution of clinical investigation, what has not changed during the 56 years since I attended my first meeting has been the ASCI's devotion to rigorous science. Membership in the Society and publication in its prestigious journal remain twin badges of honor, which are so very important at a time when we are witnessing increasing hype, spin, and commercialization of research.

Happy 100th ASCI! May your positive influence on clinical investigation and academic medicine continue unabated during your second century.

Address correspondence to: Eugene Braunwald, TIMI Study Group, 350 Longwood Avenue, Boston, Massachusetts 02115, USA. Phone: (617) 732-8989; Fax: (617) 975-0955; E-mail: ebraunwald@ partners.org.

1. Braunwald, E. 1975. Can medical schools remain the optimal site for the conduct
of clinical investigation? Presidential address before the 67th annual meeting of
the American Society for Clinical Investigation, Atlantic City, New Jersey, 5 May 1975. J. Clin. Invest. 56:i-vi.

\title{
The old Atlantic City meetings
}

\author{
Arnold S. Relman
}

Department of Medicine and Department of Social Medicine, Harvard Medical School, Boston, Massachusetts, USA.

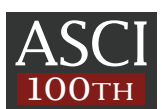

\begin{abstract}
Where once the annual meeting of the American Federation for Clinical Research, the American Society for Clinical Investigation, and the Association of American Physicians could unite the whole of clinical investigation, now stand many organizations and meetings catering to specialized fields, and the cohering effect of the Atlantic City meetings has not since been duplicated.
\end{abstract}

The annual ASCI/AAP/AFCR meetings in Atlantic City were the most important and exciting events in my early career as a clinical investigator. I started out a few years after the close of World War II, when what is now called translational medical research was expanding rapidly, and important developments in virtually every field were being reported in rapid succession. It was a heady time to be entering academic medicine, and each year all clinical researchers would meet in Atlantic City to present their latest and best work and to meet on the Boardwalk or in local hotels with their colleagues from all over the country.

The scientific excitement and the camaraderie of those meetings were unmatched. Atlantic City was where you measured your scientific success (or failure) against that of others in the field. It was where you discussed your research with your friends and your competitors and where academic careers were shaped - and much gossiped about. It was a time when you could personally know just about everyone in your field and when it was possible to gain a comprehensive overview of the current state of research in the whole field simply by attending the specialty sessions of this one meeting. Everyone who was anyone working in any area of clinical research simply had to be there.

The general sessions afforded an opportunity to hear about the latest and most important work in other fields and to see the leaders of academic medicine in action. For young people starting their careers

Conflict of interest: The author has declared that no conflict of interest exists. Citation for this article: J. Clin. Invest. 118:1230 (2008). doi:10.1172/JCI34651. in research, nothing matched the spectacle that unfolded each spring in Atlantic City. It was a meeting that not only defined the current state of clinical investigation, but also told you whether and how your own work was contributing to progress in the field. It was also, in those innocent days, a meeting largely free of commercial influences; virtually none of the thousands of researchers in attendance had any personal financial interest in the fruits of their work.

Of course, those meetings inevitably had to change. With the explosive growth of medical research in so many new directions and the entrance of so many thousands of new investigators, it simply wasn't possible to hold it all together in one meeting. Innumerable new scientific subspecialties, new societies, and specialized meetings have now supplanted the old meetings in Atlantic City, and any semblance of unity and coherence in medical research has disappeared. Dispersion and subspecialization are now the rule in clinical investigation, as in all of science. I suppose that is the price we must pay for progress, but I can't help feeling nostalgic for the ASCI/AAP/AFCR big show. Those annual pilgrimages to Mecca on the New Jersey shore held us all together in a way that has not since been duplicated. And they were a powerful reminder that clinical investigation is critical for the understanding, treatment, and prevention of human disease, therefore requiring the involvement of physicians.

Address correspondence to: Arnold S. Relman, Channing Laboratory, 181 Longwood Avenue, Boston, Massachusetts 02115, USA. Phone: (617) 525-2185; Fax: (617) 525-2186; E-mail: arelman@ rics.bwh.harvard.edu. 